\title{
Estratégias para o Aprimoramento Contínuo do Cadastro Único: Plano de Monitoramento da Gestão Municipal
}

Ana Gabriela Filippi

Sambiase ${ }^{1}$

Bruna Barreto Bastos ${ }^{2}$

Keli Rodrigues de Andrade $^{3}$

1 Departamento do Cadastro Único da Secretaria Nacional de Renda de Cidadania, Ministério do Desenvolvimento Social e Combate à Fome.

2 Departamento do Cadastro Único da Secretaria Nacional de Renda de Cidadania, Ministério do Desenvolvimento Social e Combate à Fo

3 Departamento do Cadastro Único da Secretaria Nacional de Renda de Cidadania, Ministério do Desenvolvimento Social e Combate à Fome.

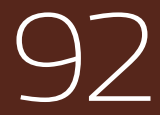

\section{Introdução ${ }^{4}$}

O Cadastro Único para Programas Sociais do Governo Federal (Cadastro Único) é instrumento para identificação, caraterização e inclusão de famílias de baixa renda 5 em programas sociais das três esferas de governo. Hoje, o Cadastro Único contém informações de mais de 80 milhões de pessoas, ou seja, 40\% da população brasileira. Em função do aumento da quantidade de programas que utilizam sua base de dados para seleção e acompanhamento de beneficiários, o Departamento do Cadastro Único (Decau) da Secretaria Nacional de Renda de Cidadania (Senarc), responsável pela gestão nacional do Cadastro Único no âmbito do Ministério de Desenvolvimento Social e Combate à Fome (MDS), vem trabalhando para que a qualidade do Cadastro Único seja aprimorada continuamente.
Neste viés, é crucial o desenvolvimento de estratégias que possam subsidiar os gestores municipais nas ações de cadastramento, bem como os gestores estaduais nas ações de apoio técnico aos municípios para melhoria da gestão dos processos de cadastramento. Nesta perspectiva, desde o ano de 2013 o Decau vem desenvolvendo o Plano de Monitoramento da Gestão Municipal do Cadastro Único (Plano de Monitoramento).

O Plano de Monitoramento é composto de uma série de atividades articuladas entre as gestões federal, estaduais e municipais do Cadastro Único, visando ao aprofundamento de análises quantitativas, expressas por indicadores de monitoramento, bem como pela ampliação de espaços para reflexão e debate acerca das experiências, 
gargalos e êxitos obtidos na gestão do

Cadastro Único, com vistas à efetiva melhoria dos processos de gestão.

O Plano de Monitoramento teve como um de seus pontos centrais a aplicação de um questionário aos municípios que apresentaram as maiores Taxas de Atualização Cadastral, com o objetivo de diagnosticar os fatores que possam estar relacionados aos bons resultados desse indicador. 0 objetivo deste texto é contextualizar os objetivos e a elaboração do questionário no Plano de Monitoramento e apresentar seus principais resultados, que subsidiarão as etapas subsequentes do Plano, a serem realizadas ao longo de 2014.
O Plano de

Monitoramento da Gestão Municipal do Cadastro Único

A formulação do Plano de Monitoramento envolveu uma série de atividades que incluíram a contratação de uma consultoria específica para estudo de indicadores, a criação de um Grupo do Trabalho no âmbito do Decau e a realização de encontros regionais com gestores estaduais.

Como etapa inicial, o Plano de Monitoramento definiu um conjunto de cinco indicadores ${ }^{6}$ para balizar o processo de acompanhamento da gestão municipal.

4 Participaram da implementação do Plano de Monitoramento da Gestão Municipal os seguintes servidores do MDS: Ana Gabriela Filippi Sambiase, Bruna Barreto Bastos, Bruno Gontyjo do Couto, Fernando Eleto Coelho, Laís Maranhão Santos Mendonça, Liomar Leite de Morais Lima e Keli Rodrigues de Andrade. Também teve participação neste trabalho a consultora da Unesco Diana Barbosa.

5 Para o Cadastro Único, famílias de baixa renda são aquelas com renda per capita de até 1/2 salario mínimo ou renda familiar total de até três salários mínimos.

6 Taxa de Atualização Cadastral: Número de famílias cadastradas com renda mensal per capita de até $1 / 2$ salário mínimo com cadastro atualizado, dividido pelo total de famílias cadastradas com renda mensal per capita de até $1 / 2$ salário mínimo, multiplicado por cem.

Taxa de Cobertura: Número de famílias cadastradas com renda mensal per capita de até $1 \frac{1}{2}$ salário mínimo, dividido pela estimativa de famílias com renda mensal per capita de até $1 \frac{1}{2}$ salário mínimo, multiplicado por cem.

Taxa de Cobertura dos Cadastros Atualizados: Número de famílias cadastradas com renda mensal per capita de até 1/2 salário mínimo com cadastro atualizado, dividido pelo total de famílias cadastradas, multiplicado por cem.

Taxa de Famílias Cadastradas com "Perfil Cadastro Único": Número de famílias cadastradas com renda mensal per capita de até $1 \frac{1}{2}$ salário mínimo, dividido pelo total de famílias cadastradas, multiplicado por cem.

Taxa de Inclusão Cadastral: Número de famílias incluídas no último mês dividido pelo total de famílias cadastradas no mês de referência, multiplicado por cem.

Revista Brasileira de Monitoramento e Avaliação | Número 6 | Julho-Dezembro de 2013 
Dentre estes, a taxa de Atualização Cadastral foi definida como Indicador-Chave para o processo de monitoramento, dada a confiabilidade conceitual e metodológica desta taxa, e também pela relevância dos índices de atualização cadastral, que configuram um dos mais importantes balizadores da rotina diária de gestão do Cadastro Único.

Em um segundo momento, com vistas a identificar padrões e dissensos que pudessem contribuir para o entendimento de diferenças significativas nas Taxas de Atualização Cadastral observadas entre municípios brasileiros, optou-se por trabalhar com dois grupos: municípios com as melhores Taxas de Atualização Cadastral e aqueles com os menores índices de Atualização Cadastral. A seleção destes municípios visou à criação de um universo que possa ser acompanhado de forma mais sistemática e aprofundada, possibilitando a identificação de pontos fortes e gargalos na gestão do Cadastro Único.

Inicialmente, utilizando-se como referência a base de dados do Cadastro Único de agosto de 2012, foram selecionados os municípios com bom desempenho no indicador de Atualização Cadastral. Para tanto, os municípios foram estratificados em cinco grupos relativos ao número de habitantes (portes) e, para cada estado, foi calculada a média do indicador em cada um dos portes populacionais. A partir deste cálculo, foram selecionados até cinco municípios com as melhores Taxas de Atualização Cadastral em cada um dos portes dos 26 estados.

Em média, foram selecionados 16 municípios por estado, distribuídos entre os cinco portes. Contudo, alguns estados ficaram significativamente abaixo desse resultado, pois em alguns deles não foi encontrado um número suficiente de municípios que satisfizesse as condições de seleção em cada estrato (Taxa de Atualização Cadastral acima do índice médio alcançado no estado e no porte).

Ao todo, foram selecionados 421 municípios com boas Taxas de Atualização Cadastral. A tabela a seguir traz a distribuição deste universo por porte:

\section{- TABELA 1: DISTRIBUIÇÃO DOS MUNICÍPIOS COM MELHOR DESEMPENHO POR PORTE - 2013}

\begin{tabular}{|c|c|c|c|c|}
\hline PORTE (Nº DE HABITANTES) & $\begin{array}{l}\text { No TOTAL DE } \\
\text { MUNICÍPIOS }\end{array}$ & $\begin{array}{l}\text { No DE MUNI- } \\
\text { CÍPIOS SELE- } \\
\text { CIONADOS }\end{array}$ & $\begin{array}{l}\text { \% DE MUNICÍ- } \\
\text { PIOS SELECIO- } \\
\text { NADOS }\end{array}$ & $\begin{array}{l}\text { No DE MUNICÍ- } \\
\text { PIOS SELECIO- } \\
\text { NADOS/TOTAL } \\
\text { DE MUNÍCIPIOS } \\
\text { SELECIONADOS }\end{array}$ \\
\hline 1. Até 5.000 & 1.298 & 85 & $6,55 \%$ & $20,19 \%$ \\
\hline 2. Mais de 5.000 a 20.000 & 2.598 & 128 & $4,93 \%$ & $30,40 \%$ \\
\hline 3. Mais de 20.000 a 100.000 & 1.381 & 117 & $8,47 \%$ & $27,79 \%$ \\
\hline 4. Mais de 20.000 a 100.000 & 250 & 75 & $30,00 \%$ & $17,81 \%$ \\
\hline 5. Mais de 500.000 & 38 & 16 & $42,11 \%$ & $3,80 \%$ \\
\hline Total & 5.565 & 421 & $7,57 \%$ & $100,00 \%$ \\
\hline
\end{tabular}


Numericamente, os Portes II e III são maioria neste grupo. Os Portes I, IV e, principalmente, o V são os menos expressivos em termos absolutos. Vale notar, no entanto, que os 16 municípios de Porte V com melhor desempenho neste indicador correspondem a $42 \%$ de todos os municípios brasileiros com mais de 500.000 habitantes. Essa proporção cai nos demais estratos, alcançando seu menor índice nos municípios de Porte II (representam menos de $5 \%$ do total de municípios brasileiros neste porte).

Se analisada a distribuição destes municípios segundo a região brasileira, a Região Nordeste, apesar de deter o maior quantitativo de municípios, teve apenas 8,86\% municípios selecionados. A maior representação proporcional está no Norte, onde os 74 municípios correspondem a $16,48 \%$ do total, seguida pela Região Centro-Oeste (11,59\%). As Regiões Sudeste e Sul tiveram, respectivamente, $4,7 \%$ e $5,3 \%$ dos seus municípios representados.

Diante destes resultados, o Decau realizou, em março de 2013, a $1^{\text {a }}$ Oficina de Monitoramento da Gestão do Cadastro Único, que contou com a participação dos gestores estaduais.

O Plano de Monitoramento pactuado neste encontro foi composto por um conjunto de seis grandes ações articuladas, envolvendo os três entes federados, a saber: (i) desenvolvimento do aplicativo Monitora; (ii) aplicação de um questionário exploratório ao grupo de municípios selecionados com os melhores resultados em relação à Taxa de Atualização Cadastral; (iii) reuniões de trabalho com os melhores resultados em relação à Taxa de Atualização Cadastral, que abarcaram 197 municípios de 17 estados, com o objetivo de qualificar e aprofundar alguns aspectos identificados nas respostas do questionário aplicado; (iv) $2^{a}$ Oficina de Monitoramento da Gestão Municipal do Cadastro Único para reavaliação e repactuação do cronograma e das ações previstas no Plano de Monitoramento; ( $v$ ) reunião de trabalho prevista para ocorrer em 14 estados, com a participação de cerca de 250 municípios com resultados críticos no indicador Atualização Cadastral, a fim de identificar estrangulamentos na gestão local do Cadastro Único e discutir a possibilidade de implementação das boas práticas mapeadas a partir dos encontros com os municípios com bons índices de Atualização

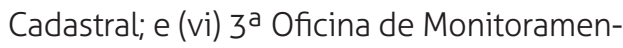
to da Gestão Municipal do Cadastro Único.

As quatro primeiras ações foram realizadas em 2013, mas somente as duas primeiras serão relatadas a seguir. As demais ações terão seus resultados consolidados no ano de 2014. 


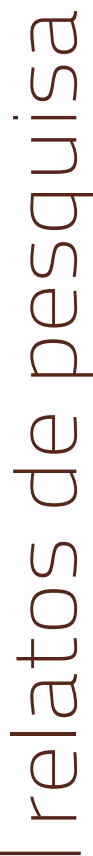

\section{I) O APLICATIVO MONITORA}

Como primeira etapa do Plano de Monitoramento, a equipe do Decau desenvolveu o Monitora. Trata-se de um aplicativo que disponibiliza dados periodicamente atualizados dos cinco indicadores definidos como centrais para o monitoramento do Cadastro Único.

O aplicativo contém informações gerais, comparadas e longitudinais sobre a gestão do Cadastro Único, possibilitando aos gestores municipais e estaduais aprimorarem as ações de monitoramento e qualificação do Cadastro Único. O Monitora está disponível na página do MDS, via Sistema de Gestão do Programa Bolsa Família (SigPBF) ${ }^{7}$. Além disso, o aplicativo permite a visualização de dados de modo agregado, por meio de gráficos, conforme exemplos acima:

É possível ainda extrair a tabela de indicadores em formato Excel, de modo a facilitar o manejo dos dados por parte dos gestores do Cadastro Único. Desde que entrou no ar (em setembro de 2013) até fevereiro de 2014, o aplicativo Monitora

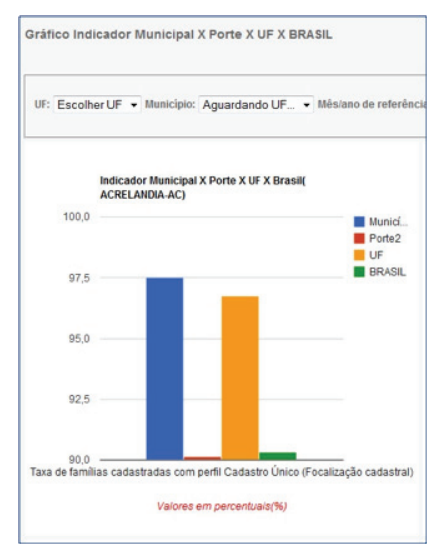

conta com mais de 8.600 visitas por parte de gestores do Cadastro Único.

\section{II) O OQUESTIONÁRIO DE GESTÃO DO CADASTRO 2013 - MONITORAMENTO MUNICIPAL}

Buscando identificar elementos relacionados aos bons resultados apresentados pelos municípios de melhores Taxas de Atualização Cadastral, foi desenvolvido o questionário "Gestão do Cadastro 2013 - Monitoramento Municipal". Trata-se de uma estratégia exploratória que buscou investigar fatores de diferentes naturezas (políticos, de infraestrutura, recursos humanos, capacitação, acesso à informação, entre outros) que poderiam estar relacionados a uma melhor gestão do Cadastro Único no município. Ou, vista de outro ângulo, a ausência desses fatores pode indicar estrangulamentos para uma boa gestão.

O questionário foi disponibilizado via SigPBF, por meio do aplicativo Sistema de Monitoramento das Atualizações Cadastrais (Simac Questionários), e ficou disponível para preenchimento pelos mu- 
nicípios selecionados no período de 29 cotidiano dos gestores municipais.

de abril de 2013 a 10 de junho de 2013.

Os resultados obtidos por meio do questionário trouxeram elementos cruciais para a definição das atividades que foram e serão desenvolvidas nas ações do Plano de Monitoramento, uma vez que apontaram aspectos que podem auxiliar no aperfeiçoamento da gestão do Cadastro Único e também explicitaram situações, características e limitações que configuram importantes gargalos vivenciados no

\section{Retorno dos municípios:}

Do universo de 421 municípios selecionados pelo desempenho positivo na Taxa de Atualização Cadastral, 278 responderam ao levantamento, o que corresponde a um retorno global de $66 \%$. A tabela abaixo demonstra um equilíbrio na taxa de retorno dos cinco portes, variando de $62,5 \%$ (Porte V) a 68,0\% (Porte II).

\section{- tabela 2: tAXA de RETORNO dOS MUNiCíPIOS COM MELHOR DESEMPENHO, POR PORTE - 2013}

\begin{tabular}{|c|c|c|c|c|}
\hline $\begin{array}{c}\text { PORTE (No DE HABI- } \\
\text { TANTES) }\end{array}$ & $\begin{array}{l}\text { No DE MUNICÍ- } \\
\text { PIOS SELECIONA- } \\
\text { DOS POR PORTE }\end{array}$ & $\begin{array}{l}\text { No DE MUNICÍ- } \\
\text { PIOS QUE RES- } \\
\text { PONDERAM AO } \\
\text { QUESTIONÁRIO }\end{array}$ & \% DE RETORNO & $\begin{array}{l}\text { No DE MUNICÍ- } \\
\text { PIOS DO PORTE } \\
\text { QUE RESPONDE- } \\
\text { RAM / TOTAL DE } \\
\text { MUNICÍPIOS QUE } \\
\text { RESPONDERAM }\end{array}$ \\
\hline 1. Até 5.000 & 85 & 57 & $67,10 \%$ & $20,50 \%$ \\
\hline $\begin{array}{l}\text { 2. Mais de } 5.000 \\
\text { a } 20.000\end{array}$ & 128 & 87 & $68,00 \%$ & $31,29 \%$ \\
\hline $\begin{array}{l}\text { 3. Mais de } 20.000 \\
\text { a } 100.000\end{array}$ & 117 & 74 & $63,30 \%$ & $26,62 \%$ \\
\hline $\begin{array}{l}\text { 4. Mais de } 20.000 \\
\text { a } 100.000\end{array}$ & 75 & 50 & $66,70 \%$ & $17,99 \%$ \\
\hline $\begin{array}{l}\text { 5. Mais de } \\
500.000\end{array}$ & 16 & 10 & $62,50 \%$ & $3,60 \%$ \\
\hline Total & 421 & 278 & $66,03 \%$ & $100,00 \%$ \\
\hline
\end{tabular}

7 O SIGPBF é um sistema que permite o acompanhamento de todas as ações de gestão relativas ao Cadastro Único e ao Programa Bolsa Família. É destinado, especificamente, aos gestores e técnicos municipais e coordenadores e técnicos estaduais que trabalham na gestão do Cadastro Único e do Programa Bolsa Família.

Revista Brasileira de Monitoramento e Avaliação | Número 6 | Julho-Dezembro de 2013 


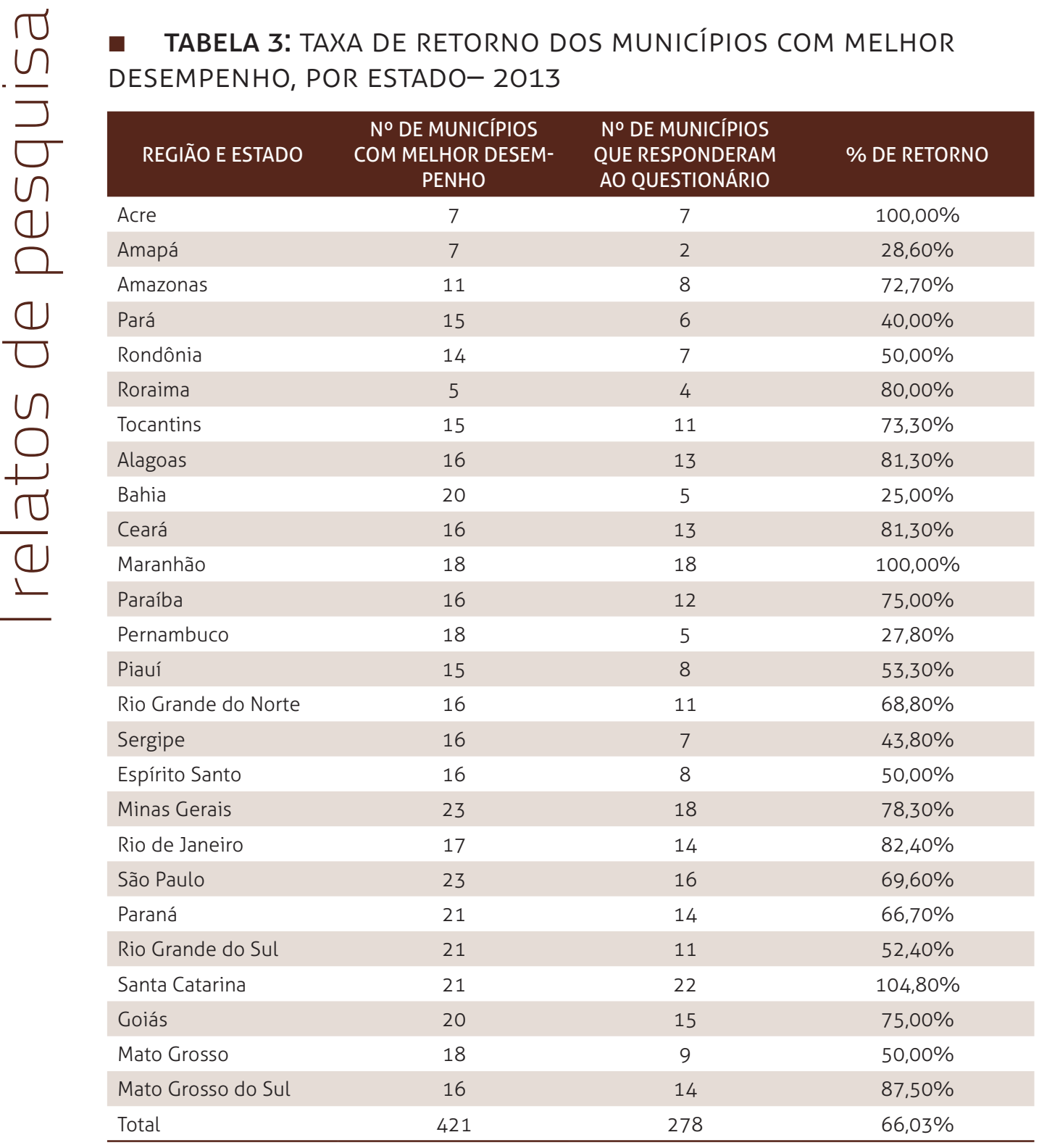

Se analisado apenas o grupo de municípios que responderam, percebe-se uma maior participação do Porte II, seguido pelo Porte III. Já a participação do Porte $V$ neste universo cai consideravelmente (3,60\%). Percebe-se acima que a distribuição, por porte, do número de municípios que responderam ao questionário é similar à distribuição, por porte, do número de municípios selecionados (última coluna da tabela 1), indicando, assim, pouco viés de resposta no que diz respeito aos portes.

No que se refere aos percentuais de devolutiva por região, observa-se uma distribuição relativamente equilibrada, sendo 
que Norte e Nordeste apresentaram resultados na casa de $60 \%$ e Sudeste, Sul e Centro-Oeste, na casa de 70\%.

Observados os percentuais de respostas segundo a distribuição por estado, houve uma variabilidade maior nas devolutivas. Nos estados do Acre, Maranhão e Santa Catarina, 100\% dos municípios selecionados responderam ao questionário. Roraima, Alagoas, Ceará, Rio de Janeiro e Mato Grosso do Sul também alcançaram boas taxas de participação de seus municípios - entre 80\% e 88\%.

\section{Resultados}

\section{A) EOUIPES DO CADASTRO ÚNICO}

No que se refere ao quadro de pessoal, buscou-se obter um desenho da composição da equipe em termos quantitativos e suas características (formação, tempo de experiência, etc.), alocação e forma de contratação.

Um primeiro elemento que merece destaque foi o fato de que a maioria $(58,3 \%)$ dos gestores do Cadastro único nos municípios com melhor desempenho em Atualização Cadastral exerce essa função há menos de 1 ano, tendo como referência a data de aplicação do questionário. Pouco mais de $27 \%$ estão no outro extremo, com 4 anos ou mais de exercício.

A princípio, este resultado poderia indicar que o tempo de atividade do responsável pelo Cadastro Único no município não seria uma variável relevante para uma boa gestão. No entanto, observou-se que, diferentemente do que acontece com a maioria dos gestores, os demais profissionais vinculados ao Cadastro Único compõem a equipe há mais de um ano na maior parte dos municípios (62\%). Deste modo, o fato de a equipe estar há mais de um ano na função pode estar associado ao bom desempenho da gestão do Cadastro Único, mesmo havendo troca do profissional responsável pelo setor.

A maioria dos gestores (51,8\%) afirma que entre 2 e 5 pessoas dedicam todo o seu tempo de trabalho a atividades diretamente associadas ao cadastramento. 0 número de profissionais em dedicação exclusiva sobe à medida que aumenta o número de habitantes do município. Aproximadamente $40 \%$ dos municípios de Porte 1 (até 5.000 habitantes) possui apenas uma pessoa trabalhando com exclusividade nas atividades do Cadastro Único, já entre os municípios de Porte 5 (mais de 500.000 habitantes), 70\% das gestões locais do Cadastro Único possuem mais de 15 funcionários de caráter exclusivo.

Quando observada a alocação destes profissionais em atividades específicas como realização de entrevistas e digitação dos formulários de cadastramento, percebese um número maior de entrevistadores em relação aos digitadores. Um percen- 
tual de $45 \%$ dos municípios têm mais de 3 entrevistadores. Se analisada a quantidade de digitadores, o percentual de munícipios que possuem mais de 3 destes profissionais cai para 32\%.

Pouco mais da metade dos gestores consideraram a quantidade de profissionais envolvidos nas atividades do Cadastro Único insuficiente. Enquanto 46,4\% deles estão satisfeitos com o quantitativo do seu quadro de pessoal, outros 53,6\% avaliam a equipe como insuficiente para a realização das atividades. Esta avaliação negativa foi preponderante entre os gestores de municípios de Porte III e IV.

Quando perguntados sobre qual seria o quantitativo suficiente de profissionais, metade dos municípios de Porte 1 disseram que este quantitativo estaria entre 4 e 5. Por sua vez, todos os gestores de municípios de porte 5 evidenciaram que o quantitativo ideal seria superior a 15 profissionais.

Em relação ao tipo de vínculo dos profissionais envolvidos nas atividades do Cadastro Único, os resultados indicam que a maioria possui contrato temporário (54\%). Este continua sendo um desafio para a estruturação do Cadastro Único e a manutenção da qualidade das informações cadastrais à medida que os contratos temporários tendem a gerar maior rotatividade da mão de obra envolvida e, com ela, menor experiência acumulada e menor capacidade das equipes. Por outro lado, indica que renovados esforços de ca- pacitação devem ser empreendidos anualmente pelo MDS, pela Caixa Econômica Federal (CAIXA) e pelas gestões estaduais, aumentando o custo dessa ação para a sociedade.

No quesito escolaridade, $49,3 \%$ dos profissionais das gestões municipais do Cadastro Único têm ensino médio e 50\% têm ensino superior. Observam-se ainda algumas variações regionais: enquanto no Norte e Nordeste predomina o ensino médio ( $71,1 \%$ e $60,9 \%$, respectivamente), a formação com ensino superior se sobressai na maior parte dos municípios das demais regiões, chegando a $74,5 \%$ no Sul.

\section{B) CAPACITAÇÃO}

Os resultados do questionário indicaram que a maioria dos municípios teve profissionais capacitados nos últimos 12 meses: $66,6 \%$ deles foram capacitados pelo MDS ou pela gestão estadual, com foco no preenchimento dos formulários e na gestão. Já 54,3\% dos municípios foram capacitados pela CAIXA sobre a Versão 7 do Sistema de Cadastro Único ${ }^{8}$.

É interessante ressaltar que a maior parte dos profissionais capacitados tende a permanecer na equipe. O nível de permanência dos profissionais capacitados chega a $84,5 \%$ nos municípios que tiveram apenas uma pessoa treinada na Versão 7 do Sistema de Cadastro Único e 80\% nas localidades onde a capacitação foi oferecida a um número maior de colaboradores (entre 6 e 10). 


\section{C) ESTRUTURA}

De modo geral, os postos de cadastramento situam-se em unidades de propriedade da prefeitura, situação encontrada em $59 \%$ dos municípios. O restante dos municípios opera em instalações alugadas.

De acordo com a maior parte dos entrevistados $(41,7 \%)$, cada município conta com dois ou três computadores de uso exclusivo para a realização de atividades do Cadastro Único e do Programa Bolsa Família. Somente 1\% (o equivalente a três municípios) não possui computador de uso exclusivo.

Todos os municípios avaliados possuem acesso à internet. Em aproximadamente $17 \%$ dos casos a conexão utilizada para acessar a Versão 7 do Sistema de Cadastro Único é de até 512 Kbps. Em 30,6\% dos casos a velocidade da conexão supera os 512 Kbps, mas não ultrapassa um Mega. A maioria dos municípios já opera com conexões mais rápidas, entre 1 e 2 Megas (29,1\%) e acima de 2 Megas (22,7\%). Contudo, somando-se as duas categorias de menor velocidade, cerca de $47,6 \%$ dos municípios ainda operam com conexões aquém da necessidade do aplicativo on line. Desta feita, avalia-se que, mesmo para os municípios de boa gestão, ainda há um gargalo substantivo de conectividade.
A instabilidade da rede compromete o trabalho de inserção e atualização de dados no sistema em 39\% dos municípios. Um total de $22,3 \%$ dos gestores responderam que algumas vezes a internet não funciona, porém isto não chega a prejudicar o trabalho. Outros 38,1\% afirmaram não haver problemas de conexão, e que a internet "está sempre funcionando".

\section{D) ORGANIZAÇÃO DAS INCLUSÕES E ATUALIZAÇÕES CADASTRAIS}

No que se refere aos processos de inclusão de novas famílias, é importante ressaltar que a visita domiciliar foi a forma mais comum de coleta de dados, mencionada em $73,7 \%$ dos municípios pesquisados. Esta é uma informação relevante, à medida que a visita domiciliar é a forma mais indicada para realização da entrevista, pois a proximidade do entrevistador com a realidade da família maximiza a qualidade da coleta de informações. O cadastramento nos Centros de Referência de Assistência Social (CRAS) e Centros de Referência Especializados de Assistência Social (CREAS) também se destacou, sendo adotado em $72,3 \%$ dos municípios. Em terceiro lugar, apareceram os postos de cadastramento na sede da gestão municipal do Cadastro Único, utilizados em $69 \%$ dos casos (esse quesito aceitava múltiplas marcações).

8 A Versão 7 do Sistema de Cadastro Único consiste em uma versão on line na qual os gestores municipais fazem a inclusão, alteração e/ou a exclusão dos dados das famílias diretamente na base nacional do Cadastro Único.

Revista Brasileira de Monitoramento e Avaliação | Número 6 | Julho-Dezembro de 2013 
Em aproximadamente $40 \%$ dos municípios não foram relatadas dificuldades por parte das famílias para o cadastramento. Nos demais, os principais problemas são a falta de informação sobre o Cadastro Único $(37,4 \%)$ e a falta de documentação civil $(31,7 \%)$.

O dado anterior pode indicar linhas de ação importantes para potencializar as ações de inclusão de famílias com perfil Cadastro Único. Por um lado, é possível desenhar ações mais efetivas de documentação civil pelo Governo Federal, por outro, é preciso divulgar mais e melhor o Cadastro Único, de forma a alcançar de fato o entendimento do público-alvo para cadastramento.

Perguntados sobre as três principais formas de atualização cadastral, os gestores elencaram: os postos de cadastramento $(47,8 \%)$, seguidos pelos CRAS/CREAS $(32,7 \%)$ e pelas visitas domiciliares, neste caso, com uma participação bem menos expressiva, equivalente a 9\% (esse quesito admitia múltiplas marcações).

Os gestores também foram questionados sobre sua percepção quanto às dificuldades das famílias para realizar a atualização cadastral. Aproximadamente $90 \%$ dos municípios identificaram dificuldades para a realização das atualizações. A maior delas seria o receio da família em perder os benefícios do Programa Bolsa Família, resposta fornecida por $81 \%$ dos municípios entrevistados. Outros 50\% alertaram para o descon- hecimento da necessidade de atualização, e $45 \%$ para a mudança de endereço (esse quesito admitia múltiplas marcações).

Estes resultados demonstram que ainda é grande a necessidade de ações de divulgação que esclareçam as regras do Cadastro Único e do Programa Bolsa Família para as famílias cadastradas, bem como sobre outros programas sociais que podem ser acessados por meio do Cadastro Único.

Com intuito de conhecer a dinâmica dos processos de entrevista, os gestores foram perguntados sobre o tempo gasto nos procedimentos de inclusão e atualização cadastral para uma família com até quatro pessoas. A maioria dos municípios leva no máximo 40 minutos para realizar a inclusão de novas famílias, enquanto são gastos, em média, 30 minutos para as atualizações cadastrais. O processo mais utilizado, seja para inclusão ou atualização, é o de cadastramento em formulário de papel, mas apenas $23 \%$ dos municípios declararam não efetuar qualquer inclusão cadastral direto no sistema. Nesse sentido, o grau de automação é grande, mas não supera o cadastramento em papel.

Questionados sobre as principais circunstâncias nas quais o município realiza visitas domiciliares, o motivo mais recorrente citado foi a averiguação de possíveis irregularidades no cadastramento advindas de denúncias $(83,0 \%)$ e a inclusão das famílias em auditorias realizadas pelo $\operatorname{MDS}(75,3 \%)$. 
Os dados indicaram ainda uma gradação na frequência com que os municípios adotam as visitas domiciliares em caso de desatualização cadastral: em primeiro lugar são priorizadas as famílias beneficiárias do PBF em situação de Revisão Cadastral (69,8\%), seguidas pelas famílias com cadastros desatualizados há mais de 24 meses (48,9\%) e por aquelas com cadastros desatualizados há mais de 48 meses (25,2\%) - o quesito admitia múltipla marcação.

Assim, o processo anual de Revisão Cadastral, que elenca as famílias beneficiárias cujos dados cadastrais foram coletados há mais de 24 meses, é a motivação mais relevante dos municípios para realizar a atualização cadastral, sobressaindo-se em relação a qualquer outra forma de organização local de processos visando à atualização cadastral. Além disso, são ainda menos priorizados os cadastros que estão há mais tempo desatualizados.

Nesse sentido, verifica-se como os mecanismos de atualização instados pelos programas usuários do Cadastro Único, em especial pelo Programa Bolsa Família, são de importância fulcral para a atualização cadastral. Basicamente, há um mecanismo de dupla determinação: cadastros não utilizados para fins de políticas públicas vigentes tornam-se cadastros inutilizáveis para esse mesmo fim, à medida que, por conta de sua desatualização, deixam de refletir a situação socioeconômica atual da família.

Por fim, buscando conhecer estratégias de mobilização que tenham resultados positivos, os gestores foram questionados sobre estratégias de comunicação adotadas para superar as dificuldades relacionadas à atualização cadastral. Dentre as múltiplas opções assinaladas, as mais recorrentes foram a divulgação de listagem das famílias que devem atualizar os dados nos postos de cadastramento $(58,6 \%)$ e a divulgação por meio de rádio (57,2\%). Destacaramse também a divulgação das listagens de famílias em escolas $(47,1 \%)$, a utilização de carros de som $(40,7 \%)$ e a colocação de cartazes em locais públicos (39,2\%).

\section{E) LIMITAÇÕES E DIFICULDADES}

A identificação de limitações e dificuldades para a gestão do Cadastro Único é um dos pontos centrais do Plano de Monitoramento. De forma geral, os problemas relacionados à Versão 7 do Sistema de Cadastro Único configuram-se como os mais frequentes na opinião dos gestores. Os erros e a indisponibilidade da Versão 7 foram apontados por $80,9 \%$ e $71,2 \%$ dos entrevistados, respectivamente. Os canais de comunicação com a CAIXA, agente operador do Cadastro Único, também estão entre as limitações percebidas por mais da metade dos municípios (52,2\%), conforme a tabela a seguir. 
- tabela 4: limitações da Gestão do CADAStro único - 2013*

\section{LIMITAÇÕES/DIFICULDADES DA GESTÃO DO CADASTRO ÚNICO}

$\% \quad \mathrm{~N} *$

\begin{tabular}{|c|c|c|}
\hline Erros do Sistema de Cadastro Único Versão 7. & $80,9 \%$ & 225 \\
\hline Indisponibilidade do Sistema de Cadastro Único Versão 7. & $71,2 \%$ & 198 \\
\hline Canais de atendimento da CAIXA insatisfatórios. & $52,2 \%$ & 145 \\
\hline Recursos humanos em quantitativo insuficiente. & $46,0 \%$ & 128 \\
\hline Meio de transporte em quantitativo insuficiente para ações do Cadastro Único. & $43,2 \%$ & 120 \\
\hline Conexão de internet insuficiente (lenta). & $34,5 \%$ & 96 \\
\hline Problemas relacionados às senhas de acesso aos sistemas do MDS. & $33,5 \%$ & 93 \\
\hline Canais de atendimento do MDS insatisfatórios. & $32,0 \%$ & 89 \\
\hline Dificuldades para encontrar as famílias. & $30,6 \%$ & 85 \\
\hline Recursos humanos pouco qualificados. & $28,1 \%$ & 78 \\
\hline Inadequação/Insuficiência de infraestrutura física para atendimento das famílias. & $28,1 \%$ & 78 \\
\hline Computadores em quantitativo insuficiente. & $24,8 \%$ & 69 \\
\hline Pouca articulação com as demais secretarias municipais. & $23,7 \%$ & 66 \\
\hline Dificuldade de acesso às listagens de famílias disponibilizadas pelo MDS. & $18,4 \%$ & 51 \\
\hline $\begin{array}{l}\text { Falta de apoio e incentivo para a gestão do Cadastro Único por parte do MDS e/ou da Coorde- } \\
\text { nação Estadual. }\end{array}$ & $15,1 \%$ & 42 \\
\hline Quantidade de demandas advindas do MDS. & $10,1 \%$ & 28 \\
\hline $\begin{array}{l}\text { Desconhecimento ou pouca compreensão da legislação, orientações técnicas e informes do } \\
\text { MDS. }\end{array}$ & $10,1 \%$ & 28 \\
\hline Período Eleitoral. & $6,8 \%$ & 19 \\
\hline Interferência de outros órgãos para o cadastramento, como o Ministério Público e o Judiciário. & $2,2 \%$ & 6 \\
\hline Outra(s). & $10,4 \%$ & 29 \\
\hline O município não enfrenta dificuldades. & $1,1 \%$ & 3 \\
\hline
\end{tabular}

* A questão permitia mais de uma marcação.

*No de municípios que responderam ao item.

F) ESTRATÉGIAS ADOTADAS PARA SUPERAÇÃO DE DIFICULDADES PERCEBIDAS

Diante das dificuldades apontadas, os gestores foram questionados sobre estratégias para mitigar as limitações enfrentadas. A compra de computadores e de outros equipamentos foi mencionada pela maior parte deles $(60,4 \%)$. Também merece destaque o investimento em alternativas em relação à falta de pessoal, como a contratação de equipe temporária para o cadastramento $(47,5 \%)$ e o desenvolvimento de parcerias para a realização de busca ativa (45,3\%).

A solicitação de apoio técnico à gestão estadual e a demanda por capacitação foram mencionadas por cerca de $1 / 3$ dos entrevistados. Apenas 13,7\% dos gestores disseram buscar interlocução permanente com o gestor federal. 


\section{- tabela 5: estratéGIAS adotadas para solução dos PROBLEMAS DA GESTÃO DO CADASTRO ÚNICO *.}

\begin{tabular}{|c|c|c|}
\hline $\begin{array}{l}\text { ESTRATÉGIAS TOMADAS, RESULTANDO EM MELHORIA OU SOLUÇÃO PARA AS LIMI- } \\
\text { TAÇÕES DA GESTÃO DO CADASTRO ÚNICO }\end{array}$ & $\%$ & $N * *$ \\
\hline Compra de computadores ou outros equipamentos de informática. & $60,4 \%$ & 168 \\
\hline Contratação de equipes temporárias/ parcerias para ações de cadastramento. & $47,5 \%$ & 132 \\
\hline $\begin{array}{l}\text { Desenvolvimento de parceria com equipes de outras políticas para ações de busca } \\
\text { ativa. }\end{array}$ & $45,3 \%$ & 126 \\
\hline Solicitação de apoio técnico da Coordenação Estadual. & $33,1 \%$ & 92 \\
\hline Mobilização/solicitação de capacitações pelo gestor estadual e federal. & $32,0 \%$ & 89 \\
\hline Contratação de serviço de internet de banda larga. & $30,9 \%$ & 86 \\
\hline $\begin{array}{l}\text { Compra de veículos (automóveis/motocicletas/barcos, etc., conforme necessidade } \\
\text { local). }\end{array}$ & $24,8 \%$ & 69 \\
\hline Reforma/construção do local de cadastramento. & $23,0 \%$ & 64 \\
\hline Desenvolvimento de estudos para identificar a população mais pobre. & $19,4 \%$ & 54 \\
\hline $\begin{array}{l}\text { Desenvolvimento de estratégias para inclusão de grupos tradicionais e específicos } \\
\text { (catadores, extrativistas, ribeirinhos, quilombolas, etc.). }\end{array}$ & $16,2 \%$ & 45 \\
\hline Realização de concurso público. & $14,0 \%$ & 39 \\
\hline Interlocução permanente com o gestor federal. & $13,7 \%$ & 38 \\
\hline Outra(s). & $10,4 \%$ & 29 \\
\hline
\end{tabular}

* A questão permitia mais de uma marcação.

$\because N^{\circ}$ de municípios que responderam ao item.

Por fim, instados a identificar as ações de maior importância para a garantia de uma boa gestão para o Cadastro Único, os gestores elegeram as ações intersetoriais como fundamentais para a efetiva gestão do Cadastro Único (82,7\%), seguidas pela elaboração de um plano de ações (45\%) e pela adoção de um modelo de capacitação continuada (44,6\%).

\section{Conclusão}

Um monitoramento exige o exame contínuo de resultados e processos de uma determinada política ou programa, que por sua vez demanda um conjunto de ferramentas e estratégias que permitam identificar tempestivamente suas vantagens e seus pontos frágeis. O desenvolvimento de um plano de monitoramento para o Cadastro Único advém de um processo de amadurecimento, cujos primeiros passos foram concretizados com a definição dos indicadores da qualidade da gestão.

Uma análise crítica destes indicadores ainda evidencia fragilidades, o que não impede a sua utilização como sinalizadores, sem a pretensão de que eles sejam assumidos como reflexo estrito da reali-

Revista Brasileira de Monitoramento e Avaliação | Número 6 | Julho-Dezembro de 2013 
dade vivenciada em todos os municípios. elementos importantes, gargalos e exO aperfeiçoamento destes instrumentos periências bem-sucedidas de gestão, de diagnóstico, que devem estar em con- subsidiou a formulação das etapas substante revisão, virá com sua utilização, sequentes do Plano de Monitoramento potencializada com o desenvolvimento da Gestão Municipal do Cadastro Único, do aplicativo Monitora, a partir do qual os em que dados foram coletados diretagestores estaduais e municipais têm acesso aos indicadores de gestão de forma sistemática e continuada. mente com os gestores municipais em reuniões presenciais.

Diante das informações coletadas, a equiA aplicação do questionário "Gestão do pe do Departamento do Cadastro Único Cadastro 2013 - Monitoramento Municido MDS identificou a necessidade de pal" para um universo determinado de aprofundar as discussões acerca de três municípios, com o objetivo de coletar pontos centrais: a) composição das equi- 
pes do Cadastro Único; b) práticas e ações que tenham surtido efeito positivo para superação de dificuldades e melhora da gestão do Cadastro Único; e c) os gargalos relacionados à operacionalização da Versão 7 do Sistema de Cadastro Único. Os dois primeiros pontos foram pauta das reuniões de trabalho com os municípios que responderam ao questionário, na etapa seguinte do Plano de Monitoramento, ocorrida ainda em 2013. Já as deficiências e entraves relacionados à tecnologia da informação subsidiaram a formatação de oficinas específicas sobre a V7, que devem ocorrer em 2014.
Os resultados do questionário foram utilizados ainda para permitir o desenvolvimento de outras ações, para além das atividades de monitoramento, visando ao aperfeiçoamento do Cadastro Único, inclusive na mobilização de outros atores na esfera federal. Os instrumentos e ações decorrentes dessa concertação serão explicitados oportunamente em outro texto.

Por fim, destaca-se o engajamento das três esferas de governo na busca da consolidação de um modelo sistemático de monitoramento, com o objetivo final de qualificar a gestão do Cadastro Único. 